\title{
Research on Fatigue Fracture Characterization of PC/ABS Blend Ming-Hsiung $\mathrm{Ho}^{1, \mathrm{a}^{*}}$, Pin-Ning Wang ${ }^{2, \mathrm{~b}}$, Jung-Peng Yeh ${ }^{1, \mathrm{c}}$ and Sheng-Jie $\mathrm{Li}^{1, \mathrm{~d}}$ \\ ${ }^{1}$ Department of Mechanical Engineering, Taoyuan Innovation Institute of Technology, Jhongli, 32054, Taiwan, R.O.C. \\ ${ }^{2}$ Department of Material and Fiber, Taoyuan Innovation Institute of Technology, Jhongli, 32054, Taiwan, R.O.C. \\ amorrisho@tiit.edu.tw, ${ }^{\text {b pnwang@tiit.edu.tw, cyjp@tiit.edu.tw, }{ }^{\mathrm{d}} \mathrm{li5} 40525 @ g m a i l . c o m}$
}

\begin{abstract}
Keywords: Compact tension specimen, PC/ABS, Blend, Injection Molding conditions, da/dn. Abstract. PC/ABS blend is widely used in the vehicle interior, electronic parts and accessories. In this dissertation, fracture crack properties of PC/ABS blend was studied. The specimens were prepared under various injections molding conditions, such as filling time, melting temperature and mold temperature. The fracture mechanisms were examined with a scanning electron microscopy. The injection molding condition of filling time 2 seconds, melting temperature $260^{\circ} \mathrm{C}$ and mold temperature $55^{\circ} \mathrm{C}$ had the slowest fracture crack propagation speed. The da/dN with $\Delta \mathrm{K}$ curves were linear regression to find out Paris's equation coefficients. The fracture mechanisms were the crack surface edge fiber pulled off, pushing back and ribbed surface rendering stripes
\end{abstract}

\section{Introduction}

PC/ABS (Polycarbonate/Acrylonitrile-Butadiene-Styrene) has a high heat resistance, impact resistance and weather resistance properties. The material usually used in automotive interior, exterior parts, precision machine parts and food industry etc. The Injection molding method has excellent surface accuracy, short processing cycle, low cost, and can be used to molding complex shapes.

$\mathrm{PC} / \mathrm{ABS}$ is product of amorphous, thermoplastic polymer blends on the basis of polycarbonate (PC) and Acrylonitrile-Butadiene-Styrene (ABS). PC/ABS combines the excellent properties of the two materials, ABS formability and PC material mechanical, impact strength, heat resistance, and resistance to weather ultraviolet (UV) properties. The material usually used in household, electrical, electronic automotive interior, exterior parts, precision machine parts and food industry etc. For parts forming methods, the injection molding method has excellent surface accuracy, short processing cycle, low cost, and can be used to molding complex shapes.

Yakut [1] design gear fatigue test for PA 66 with fiber glass plastic material. To acquire ideal working conditions with plastic-type gears, tooth load and cycle period must be selected appropriately. Lee S.K. et al. [2] studied addition of PC could have toughened recycled PMMA matrix under impact test conditions. Abuzar E.O. et al. [3] has been investigated fracture behavior of ABS polymeric material under the full range of in-plane loading conditions using a new loading device to obtain more reliable results. Li H. et al. [4] experimentally investigated the mixed-mode fracture of PC/ ABS alloy. The appearance, growth, and coalescence of crazes can be observed in the micro-fracture processes, and the macro-crack propagation direction is finally determined by the coalesced direction of crazes. Ho et al. [5] had studied fracture toughness of PC/ABS blend under various injections molding conditions.

In this study, the PC/ABS material was researched object, using injection molding method for forming a test specimen and ASTM E647 standard to explore the material propertied under different filling time, melt temperature, mold temperature. It was evaluated that the PC/ABS plastic material propertied with molding conditions and fatigue fracture testing conditions. After the experiment, the specimen fracture surfaces were examined with the scanning electron microscope, in order to understand the related fracture mechanism. 


\section{Methods}

The material used in this study is the GE (General Electric Company) produces granular $\mathrm{PC} / \mathrm{ABS}$ plastic. The material brand name is Cycoloy-C1110HF. The volume percentage of containing the PC and the ABS is $60 \%$ and $40 \%$, and the average density is $1.13 \mathrm{~g} / \mathrm{cm}^{3}$. The mold layout is shown in Fig. 1. The test specimens used in experiments are melting glue injection from the tail end.

The molding conditions about filling time were set to $2 / 6 / 12 / 14$ seconds, melt temperature were designed for $200 / 220 / 240 / 260 / 280^{\circ} \mathrm{C}$ and mold temperature were set to $35 / 50 / 65 / 80^{\circ} \mathrm{C}$. The specimen ID and the detailed of the injecting molding conditions are listed in Table 1 . The three main conditions T2, M260 and C80 were linked with same conditions. During the injection molding, the material was preheated at $110^{\circ} \mathrm{C}$ for $4-6$ hours to get rid of the moisture before it can be used in an injection molding machine. The specimens were cooled to room temperature in atmosphere, after the specimens being ejected out of the mold.

Experiment planning and methods were modified from ASTM E647-88a. The crack length and thickness of the specimen were met standard requirements. The fatigue tests were by MTS 810 $100 \mathrm{kN}$ servo-hydraulic testing machine. Conduct process is divided into two stages: (1) specimen fatigue pre-crack test, (2) fatigue crack propagation test.

The experimental conditions for the just initial injection molding crack length is $7.5 \mathrm{~mm}$, and to extend the length $9 \mathrm{~mm}$ by pre-crack process. The compact tension specimen after pre-cracking and fatigue cracks to obtain stable fatigue crack propagation phase of $\mathrm{da} / \mathrm{dN}$ value and the corresponding value of $\Delta \mathrm{K}$. Then the experimental data by means of polynomial method finishing painted in $\mathrm{da} / \mathrm{dN}$ and $\Delta \mathrm{K}$ double logarithmic graphs. Then the least squares method for curve adaptation (Curve Fitting) determined to meet the second stage of the Paris's equation and the $\mathrm{C}, \mathrm{n}$ values of fracture propagation parameters. After the test, specimen fracture surface was observed with a scanning electron microscope.

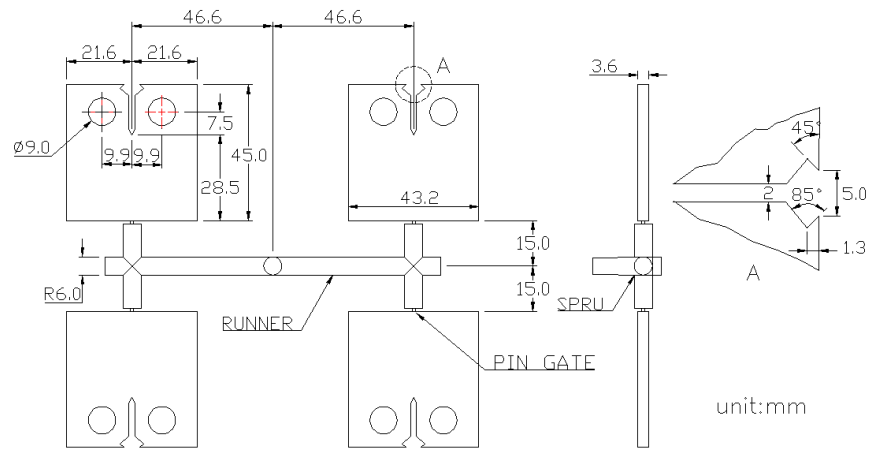

Figure 1. The layout of injection mold.

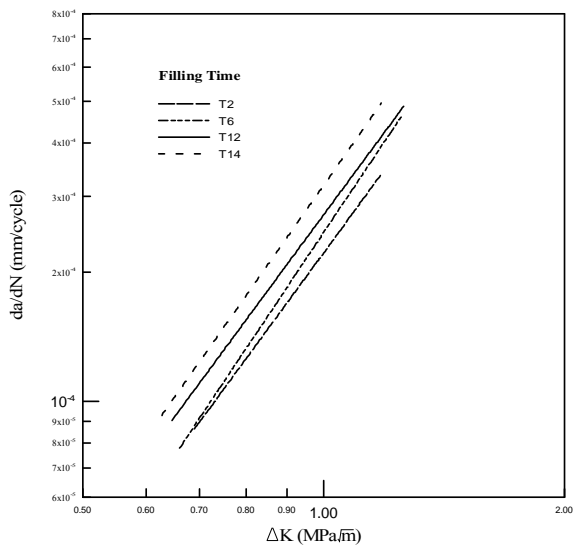

Figure 2. The melting temperature.

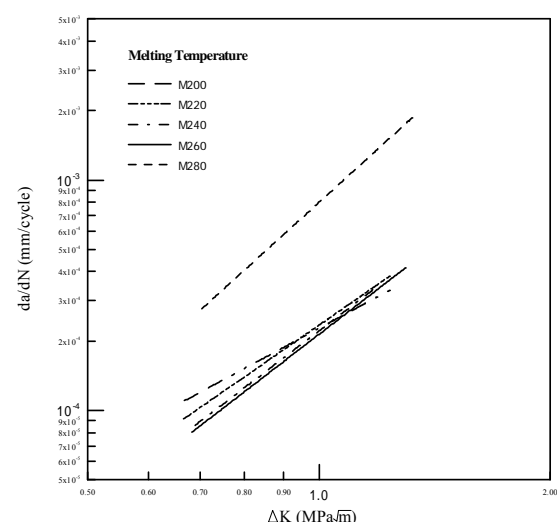

Figure 3. The melting temperature.

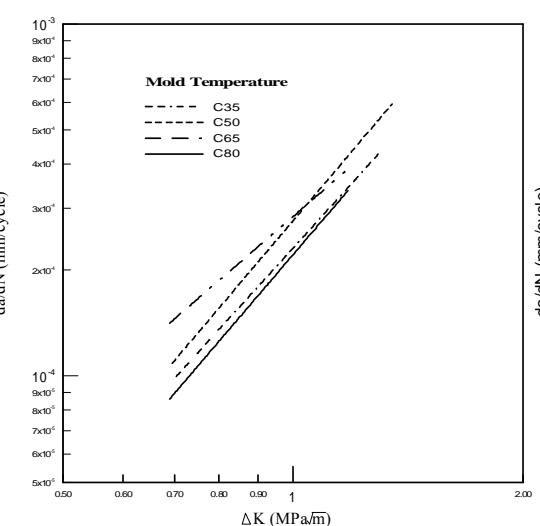

Figure 4. The mold temperature.

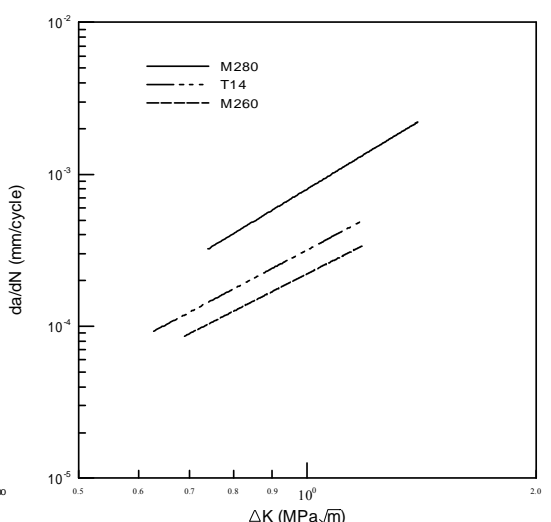

Figure 5. Molding conditions test. 
Table 1. Specimen injection mold conditions.

\begin{tabular}{|l|c|c|c|}
\hline ID & $\begin{array}{c}\text { Filling } \\
\text { time } \\
(\mathrm{s})\end{array}$ & $\begin{array}{c}\text { Melting } \\
\text { temperature } \\
\left({ }^{\circ} \mathrm{C}\right)\end{array}$ & $\begin{array}{c}\text { Mold } \\
\text { Temperature } \\
\left({ }^{\circ} \mathrm{C}\right)\end{array}$ \\
\hline $\mathrm{T} 2$ & 2 & 260 & 80 \\
\hline $\mathrm{T} 12$ & 6 & 260 & 80 \\
\hline $\mathrm{T} 14$ & 12 & 260 & 80 \\
\hline $\mathrm{M} 200$ & 2 & 260 & 80 \\
\hline $\mathrm{M} 220$ & 2 & 220 & 80 \\
\hline $\mathrm{M} 240$ & 2 & 240 & 80 \\
\hline $\mathrm{M} 260$ & 2 & 260 & 80 \\
\hline $\mathrm{M} 280$ & 2 & 280 & 80 \\
\hline $\mathrm{C} 35$ & 2 & 260 & 35 \\
\hline $\mathrm{C} 50$ & 2 & 260 & 50 \\
\hline $\mathrm{C} 65$ & 2 & 260 & 65 \\
\hline $\mathrm{C} 80$ & 2 & 260 & 80 \\
\hline
\end{tabular}

Table 2. The Paris's equation of $\mathrm{C}, \mathrm{n}$ coefficients

\begin{tabular}{|l|l|l|}
\hline Specimens & $\mathrm{C}$ & $\mathrm{n}$ \\
& & \\
\hline $\mathrm{T} 2$ & $2.21 \times 10^{-4}$ & 2.54 \\
\hline $\mathrm{T} 6$ & $3.18 \times 10^{-4}$ & 2.65 \\
\hline $\mathrm{T} 12$ & $2.47 \times 10^{-4}$ & 2.79 \\
\hline $\mathrm{T} 14$ & $2.71 \times 10^{-4}$ & 2.52 \\
\hline $\mathrm{M} 200$ & $2.27 \times 10^{-4}$ & 1.79 \\
\hline $\mathrm{M} 220$ & $2.34 \times 10^{-4}$ & 2.31 \\
\hline $\mathrm{M} 240$ & $2.13 \times 10^{-4}$ & 2.56 \\
\hline $\mathrm{M} 260$ & $2.21 \times 10^{-4}$ & 2.54 \\
\hline $\mathrm{M} 280$ & $8.00 \times 10^{-4}$ & 3.03 \\
\hline $\mathrm{C} 35$ & $2.31 \times 10^{-4}$ & 2.39 \\
\hline $\mathrm{C} 50$ & $2.76 \times 10^{-4}$ & 2.56 \\
\hline $\mathrm{C} 65$ & $2.84 \times 10^{-4}$ & 1.88 \\
\hline $\mathrm{C} 80$ & $2.21 \times 10^{-4}$ & 2.54 \\
\hline
\end{tabular}

\section{Results and Discussions}

\section{Fatigue crack growth characteristics}

From Fig. 2 to 4 are PC/ABS blend under the conditions of filling time, melting temperature and mold temperature after fracture crack propagation test. The experiment data after linear regression at $\mathrm{da} / \mathrm{dN}$ and $\Delta \mathrm{K}$ double logarithmic coordinates are linear match with Paris's equation.

The Fig. 2 was showed fill time as the main molding conditions, the influence of the conditions of filling time increases, along with increased fracture crack propagation speed. Where in the filling time of 2 seconds with minimum fracture crack propagation speed is the best condition. When the filling time was 14 seconds the highest speed of fracture crack propagation. In the previously study the results consistent with the distribution of skin layer normalization thickness.

The Fig. 3 in the melt temperature conditions, temperature from $200{ }^{\circ} \mathrm{C}$ to $260{ }^{\circ} \mathrm{C}$ fatigue crack propagation speed lines concentrated close, but can still distinguish between the fast and slow extension rates in order, is $200^{\circ} \mathrm{C}, 220^{\circ} \mathrm{C}, 240^{\circ} \mathrm{C}, 260^{\circ} \mathrm{C}$. But when the melt temperature is $280^{\circ} \mathrm{C}$, the fatigue crack propagation speed curve shifted upward, showing the fatigue fracture propagation speed is quite high, poor resistance to fracture.

When mold temperature as the main molding condition, the Fig. 4 shows that the slowest crack propagation speed is mold temperature $80^{\circ} \mathrm{C}$. The mold temperature $35^{\circ} \mathrm{C}$ has the maximum crack propagation speed, although the $\Delta \mathrm{K}$ less than 1 . This trend presents a $\mathrm{U}$-shaped change, lower point of $65^{\circ} \mathrm{C}$, on both sides of $80^{\circ} \mathrm{C}$ and $35^{\circ} \mathrm{C}$. In the mold temperature conditions, high mold temperature would make melting glue required longer cooling time, and the molecular growth forward would be better. The material ductility will increase, but the energy required to maintain the mold temperature consume more energy relatively. Low mold temperature during the molding process will cause the plastic melt cooled and solidified quickly, so that the arrangement direction of melt glue would be disorder. And mold temperature of 35 and $50^{\circ} \mathrm{C}$, the surface temperature is too low to cause solidification at the molding.

Comprehensive three molding conditions test results in Fig. 5, the slowest fracture crack propagation speed M260 (i.e. filling time 2 seconds, mold temperature $80^{\circ} \mathrm{C}$ ). The highest fracture crack propagation speed is $\mathrm{M} 280$ (i.e. the filling time of 2 seconds, mold temperature $80^{\circ} \mathrm{C}$ )

Table 2 lists the Paris's equation of $\mathrm{C}$, n coefficients under various molding conditions.

\section{Fatigue crack propagation mechanism}

In Fig. 6 the fracture propagation area in core layer organization, was showed obvious fatigue striations, patch (Patchwork) material like tissue in the fracture extends to the process, represents 
the crack surface edge fiber pulled off, pushing back the organization.

Fig. 7 is for the melting temperature of $280^{\circ} \mathrm{C}$ fatigue crack extension region epidermis tissue. In this figure can be clearly observed fatigue striations, fatigue affected the load in plane shear stress caused by the type of damage and the ribbed surface rendering (Rib-Like) stripes.

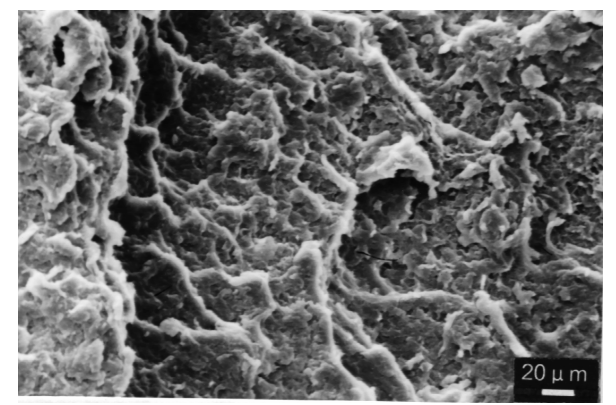

Figure 6. The fracture surface of M260.

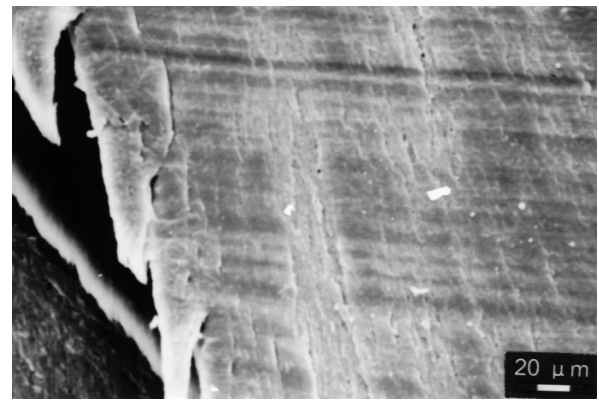

Figure 7. The fracture surface of M280.

\section{Conclusion}

The mold process conditions of this study for a comprehensive PC/ABS blend fatigue crack propagation can be summarized as follows:

1. Fatigue fracture propagation characteristics of PC/ABS plastic material can also be combined with Paris equation like expression as metal materials.

2. The lowest speed of the fatigue crack propagation is filling time 2 seconds, melting temperature $260^{\circ} \mathrm{C}$, at mold temperature of $80^{\circ} \mathrm{C}$. Its Paris' equation of $\mathrm{C}$ is $2.21 \times 10^{-4}$ and $\mathrm{n}$ is 2.54 .

3. The maximum speed of filling time condition 2 seconds, the temperature of melting glue $280^{\circ} \mathrm{C}$, a mold temperature of $80^{\circ} \mathrm{C}$. Its Paris' equation of $\mathrm{C}$ is $8.00 \times 10^{-4}$ and $\mathrm{n}$ is 3.03 .

4. The main fracture mechanism in fatigue crack extension region was showed a ribbed stripe and obvious fatigue striations, patch material like tissue.

\section{Acknowledgement}

In this paper, the research was sponsored by the National Science Council (Project No. MOST 104-2221-E-253-004)

\section{References}

[1] R. Yakut, H. Düzcükoglu, Examining the Abrasion Behaviour of PA 66 Gears in Different Cycles, Adv. in Mater. Sci. and Eng. 2014 (2014) 1-5.

[2] S.K. Lee, Mechanical Properties and Fracture Morphology of Blends of PC with PMMA, Inter. Poly. Proc. 27 (2012) 626-630.

[3] E.O. Abuzar, Experimental and numerical investigation of fracture of ABS polymeric material for different sample's thickness using a new loading device, Poly. Eng. \& Sci. 54 (2014) 2086-2096.

[4] H. Li, Experimental investigation on the essential work of mixed-mode fracture of PC/ABS alloy, J. of Mech. Sci. and Tech., 29 (2015) 33-38.

[5] M.H. Ho, P.N. Wang, J.P. Yeh, Research on the Fracture Toughness of PC/ABS Blend, submitted to Adv. in Eng. and Tech. (2015) 